\title{
Liquid Surface Divertor Designs for Fusion Reactors
}

R.E. Nygren, T.D. Rognlien, M.E. Rensink, S.Smolentsev, B.E. Nelson, P.J. Fogarty, C. Eberle, M.A. Ulrickson

November 12, 2003

20th Symposium on Fusion Engineering

San Diego, CA, United States

October 14, 2003 through October 17, 2003 
This document was prepared as an account of work sponsored by an agency of the United States Government. Neither the United States Government nor the University of California nor any of their employees, makes any warranty, express or implied, or assumes any legal liability or responsibility for the accuracy, completeness, or usefulness of any information, apparatus, product, or process disclosed, or represents that its use would not infringe privately owned rights. Reference herein to any specific commercial product, process, or service by trade name, trademark, manufacturer, or otherwise, does not necessarily constitute or imply its endorsement, recommendation, or favoring by the United States Government or the University of California. The views and opinions of authors expressed herein do not necessarily state or reflect those of the United States Government or the University of California, and shall not be used for advertising or product endorsement purposes. 


\title{
Liquid Surface Divertor Designs for Fusion Reactors
}

\author{
R.E. Nygren ${ }^{\mathrm{a}}$, T.D. Rognlien ${ }^{\mathrm{b}}$, M.E. Rensink ${ }^{\mathrm{b}}$, S. Smolentsev ${ }^{\mathrm{c}}$, B.E. Nelson ${ }^{\mathrm{d}}$, P.J. Fogarty ${ }^{\mathrm{d}}$, \\ C. Eberle $^{\mathrm{d}}$, M.A. Ulrickson ${ }^{\mathrm{a}}$ \\ ${ }^{\text {a }}$ Sandia National Laboratories", PO Box 5800, Albuquerque, NM 87185 \\ ${ }^{\mathrm{b}}$ Lawrence Livermore National Laboratory, 7000 East Ave., Livermore, CA 94550 \\ ${ }^{\mathrm{c}}$ University of California, Los Angeles, MAE Dept. Box 951597, Los Angeles, CA 90095-1597 \\ dOak Ridge National Laboratory, P.O. Box 2008, Oak Ridge, TN 37831
}

\begin{abstract}
As part of work in the US on free flowing liquid surfaces facing the plasma, we are studying issues of integrating a liquid surface divertor into a configuration based upon an advanced tokamak (ARIES-RS). The simplest form of such a divertor is to extend the flow of the liquid first wall and avoid introducing any separate fluid streams. A design and some of the issues in design integration are presented for a divertor (and first wall) with the molten salt Flinabe, a mixture of lithium and sodium fluorides. Thermal performance and the interactions with the plasma edge are treated. Sn and Sn-Li have also been considered, although the complicated 3-D MHD flows cannot yet be fully modeled.
\end{abstract}

\section{INTRODUCTION}

The goal of an attractive path for commercializing fusion energy has prompted research on designing fusion chambers with high power density and liquid wall facing the plasma in the APEX[1] and ALPS[2] Programs. Our work in APEX has included chamber designs with flowing Li, Flibe, Sn or $\mathrm{Ga}$, for first wall and divertor, as well as Flinabe, and, with each design, detailed CAD renderings and innovative features, such as "self shielding" nozzles[4] in Fig. 1 on the next pag e. This paper summarizes progress on various aspects of the design for the extended flow of the molten salt Flinabe from the FW that forms a divertor stream. A companion paper[3] summarizes the molten salt chamber design and longer papers elsewhere[4,5] give more detail and references.'

Flinabe is a mixture of lithium, beryllium and sodium fluorides and has similarities to Flibe. We assume the heat transfer properties of Flinabe are those of Flibe. Flinabe's lower melting point (still an open question) that extends the window of operating temperature enough that a workable design appears possible. We began this design with some skepticism since molten salts generally have poor thermal conductivity and good thermal conductivity would seem to be an a priori requirement for any first wall and divertor material.

We adapted the mechanical configuration of ARIES-RS ${ }^{1}[6,7]$ to incorporate a liquid surface first wall (FW) and divertor and a liquid blanket and specified a fusion power of $3840 \mathrm{MW}$, alpha power of $767 \mathrm{MW}$ and auxiliary power of $142 \mathrm{MW}$ to define higher heat loads than ARIES-RS. Fig. 1 shows the

\footnotetext{
*Sandia is a multi-program laboratory operated by Sandia Corporation, a Lockheed Martin Company, for the United States Department of Energy under Contract DE-AC04-94AL85000.

${ }^{1}$ ARIES-RS is a $2170 \mathrm{MW} \mathrm{D} / \mathrm{T}$ conceptual power plant design with $16 \mathrm{TF}$ coils, a major radius of $5.5 \mathrm{~m}$, an aspect ratio of 4 , a plasma current of $11 \mathrm{MA}$, density of $2 \times 10^{20} \mathrm{~m}^{-3}$, alpha power of $433 \mathrm{MW}$ and total power exhausted into the scrape-off layer or (and) radiated of 532MW.[6,7]
}

$2 \mathrm{~cm}$-thick flowing first wall stream ${ }^{2}$ introduced from an array of "self shielding" nozzles[4] that have no direct line-of-sight from the plasma. The FW flows on a substrate that is the wall of a blanket that contains a slower flowing liquid breeder (Flibe or Li-Pb). A drain duct in each sector of the torus collects fluid flow and is a particle exhaust port. Our current design for the divertor has a solid deflector upstream of the strike point. This deflector separates the toroidally continuous FW flow into one stream for each sector, promotes thermal mixing and increases the turbulence and directs the stream into the exhaust duct. The $5 \mathrm{~mm}$-thick deflector is made of a copper alloy clad in ferritic steel to match other structure. An alternate design is a deflector of advanced (low activation) ferritic steel with internal coolant passages fed by an auxiliary coolant stream that could be exhausted into the divertor.

\section{PLASMA EDGE MODELING \& POWER HANDLING}

Radiating a high fraction of the particle power is essential for the design approaches described here. Plasma edge modeling by Rognlien and Rensink[4,5,8,9] with the 2D UEDGE code provides particle loads and the power deposition profiles in the divertor. Vaporization from the liquid surfaces, the primary source of plasma impurities, depends exponentially upon temperature, so there is a narrow range in which the impurity generation rate changes from low to unacceptable. For Flibe (or Flinabe), the penetration into the plasma of $\mathrm{F}$, the most dangerous core-contamination component of Flibe, occurs after the breakup of evaporated molecules that produce neutrals with velocities much greater than those associated with evaporation. The UEDGE modeling is complemented by that of Brooks using a sheath model with 3-D capability called BPHI-3D[10-13] to evaluate effects within the plasma sheath at the divertor and the WBC code for near-surface transport of sputtered impurities[14]. Our longer paper[4] also notes modeling of Li walls, in which the $\mathrm{Li}$ is assumed to be an active sink for hydrogen and severely reduces the recycling at the edge, modeling with Sn walls, and modeling with Flibe as well as theoretical and experimental research on the physical response of liquid surfaces, such as Li surface segregation, that affect their sputtering, erosion and redeposition.

In our reactor chamber design, $767 \mathrm{MW}$ goes to the first wall from both core and edge radiation, and $144 \mathrm{MW}$ goes to the divertor as radiation or deposited particles. Figure 2 shows a stable solution of the model for $480 \mathrm{MW}$ of convected power from the core that corresponds to our reference design. This extremely pleasing result, with a stable and highly radiating

\footnotetext{
${ }^{2}$ Neil Morley and others at UCLA introduced the idea of a thin flowing first wall with a secondary flow stream for the blanket in APEX by their "Concept for a Li Flowing First wall" or CLIFF.
} 


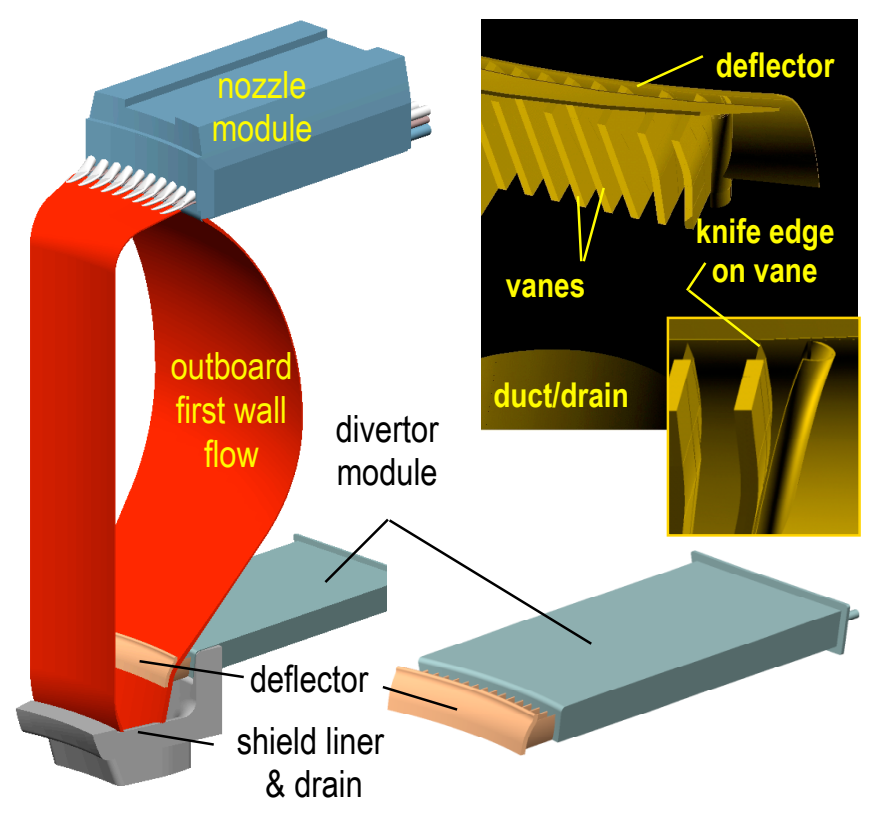

Figure 1. Outer divertor with deflector upstream of strike point

plasma edge, is the basis for our divertor design with a modest peak heat flux of $\sim 10 \mathrm{MW} / \mathrm{m}^{2}$. An important caveat regarding the plasma edge modeling is that the stability of such highly radiating edge-plasmas. An operating window exists, but outside this window, the edge impurities can either lead to a radiation collapse of the core, or become ineffective in the edge, thereby allowing a large particle heat-flux to reach the divertor.

Liquid surfaces present several intriguing issues with regard to pumping that are described in our longer paper[4]. Although the applications for trapping impinging $\mathrm{D} / \mathrm{T}$ or $\mathrm{He}$ ions are quite speculative at this time, the underlying ideas do have good scientific bases. Here are two examples. (1) In a reactor with $\mathrm{Li}$ walls that strongly pumped $\mathrm{D}$ and $\mathrm{T}$ (very low recycling), one might expect plasmas with very high edge temperatures that in turn affect the plasma performance and power balance. (2) With a continuing strong flux of $\mathrm{H}$ or $\mathrm{He}$ into the liquid surface, the liquids may trap $\mathrm{He}$ or $\mathrm{H}$ through the creation and growth of tiny bubbles, whereas this would not occur at lower fluxes. This prospect might lead to designs in which the pumping port used for evacuation of the vessel need not be close to the edge of the plasma.

Our design[4] uses "conventional" pumping through the bottom ducts in which the draining fluid occupies only a small portion of the cross section. The ducts provide adequate conductance for the modeled $\mathrm{D} / \mathrm{T}$ throughput and pressure in the divertor of $\sim 3 \mathrm{mT}$ Torr based on a simple conductance estimate. (A better estimate of the pumping could be obtained with a Monte Carlo calculation for our divertor configuration and a specified plasma edge condition.) The pumping of $\mathrm{He}$ was judged adequate based on the 2-D modeling of He density in a high recycling divertor, which we assume for Flibe, Flinabe and liquid Sn, and adequate pumping of the D/T. However, our assertion that the pumping conductance is adequate for a high recycling divertor must be qualified in regard to both the control of pumping and the condition of

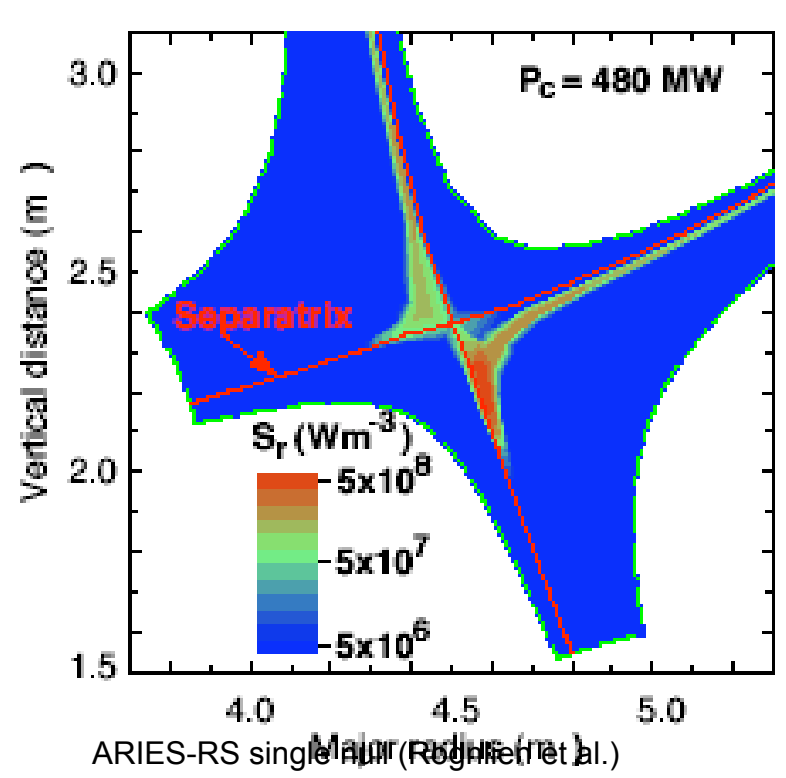

Figure 2. UEDGE “maps" of fluorine radiation. See text for explanation.

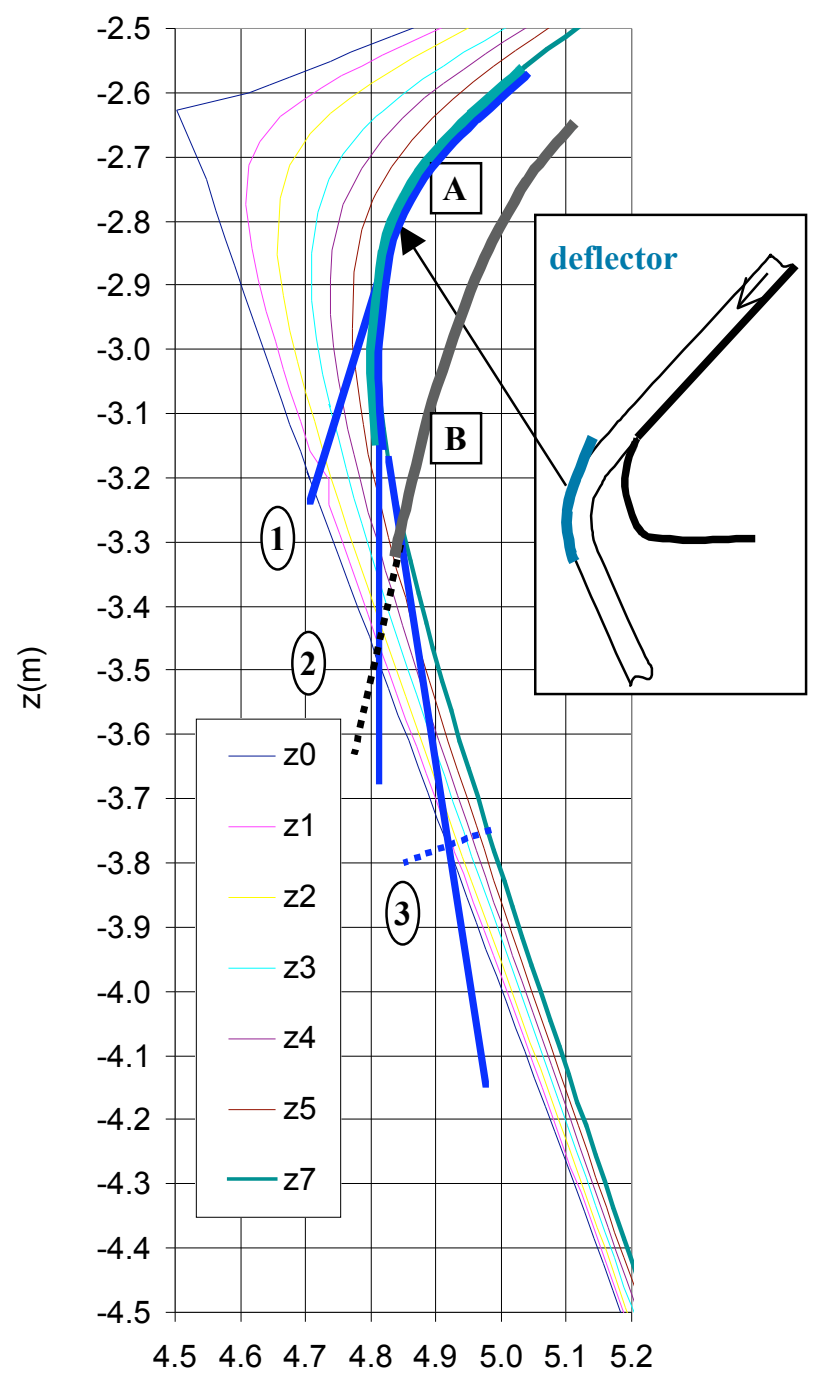

Figure 3. Portion of a flux map for ARIES-RS with a single null divertor (by Bulmer and Roglien, LLNL) overlaid with positions studied for a free surface divertor stream. 


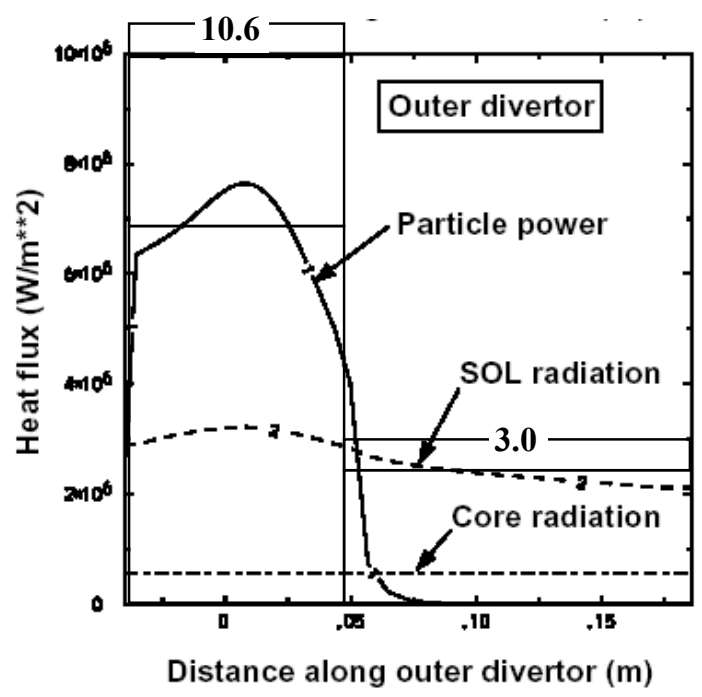

Figure 4. Heat load profiles for the divertor from UEDGE and average values for peak and background used in Smolentsev's calculations.

high recycling. The plasma edge modeling solution for the desired power balance in our design was achieved without gas puffing at the edges and with high recycling but very low throughput. We can anticipate that such a solution might be sensitive to "excess pumping" in the divertor. Since this is the $\mathrm{n}^{\text {th }}$-of-a-kind power plant, we assume that the proper pumping balance has been achieved.

\section{POWER HANDLING}

We are evaluating two classes of coolants, liquid metals $(\mathrm{Li}$, $\mathrm{Sn}, \mathrm{Sn}-\mathrm{Li}$ or Ga), and molten salts (Flibe and Flinabe). ${ }^{3}$ The thermal and electrical conductivities are high for liquid metals. The heat penetrates primarily by simple conduction. MHD forces control the flow and are an active area of investigation in APEX[22]. Sn and Ga showed promise as coolants for a single stream first wall and divertor in preliminary evaluations.[4]

A liquid surface passing through the divertor at $10 \mathrm{~m} / \mathrm{s}$ spends only a few milliseconds under the peak heat load. The short exposure is the reason that relatively high peak heats loads can be considered with liquid surface divertors. With moderate peak heat loads, fluids with relatively poor thermal conductivity, such as Flinabe, can be considered; more specifically, since there are minimal MHD effects due to the low electrical conductivity, turbulent heat transfer partially mitigates the disadvantage of low thermal conductivity.

Fig. 3 (previous page) shows flux surfaces (from Rognlien, Rensink and Bulmer) with two possible positions of a deflector located outside the outermost flux surface on this map (z7=70mm.). Deflector A lies on the flux surface and Deflector B is lower. By making the arc of Deflector A shorter or longer, the stream can be redirected over a range of angles. Three such streams from Deflector A cross the separatrix at points 1, 2, or 3. One stream from Deflector B also crosses at point 2 , but at a higher angle $\left(\sim 45^{\circ}\right)$. Tilting the target can spread the heat over a larger area but this spread

${ }^{3}$ Ref. [4] gives more detail and references regarding heat transfer with liquid
metals and physical properties of these and the molten salts Flibe and Flinabe.
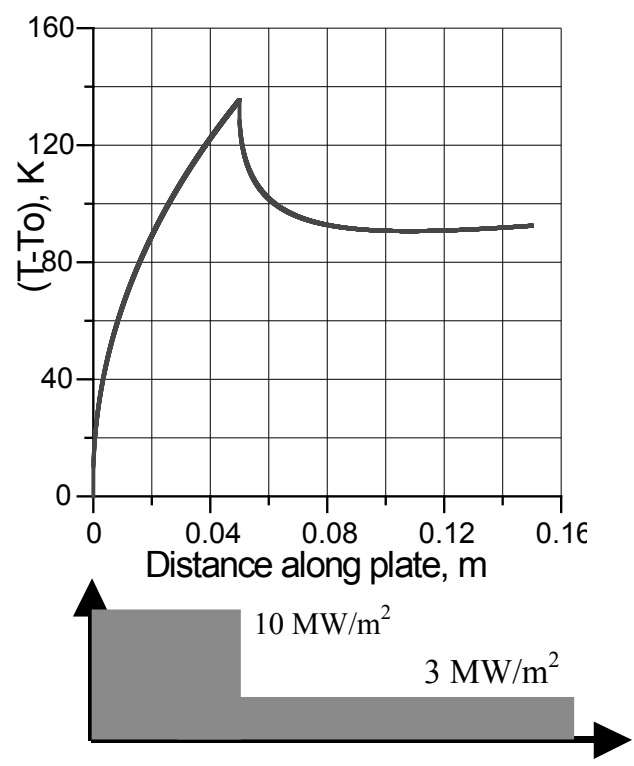

Figure 5. Temperature rise of Flinabe in divertor vs. distance along flow.

also depends on the flux expansion, which decreases from Point 1 to Point 3. Position 1 has the lowest value of the temperature rise factor, $\quad(\sin (\square) / f l x p)^{4}$, for any given angle of the deflected flow, but Position 3 can have the lowest factor overall because that position can attain the smallest target angle.[4]

In evaluating the heat removal in the single null Flinabe divertor, we apply a flat profile with a peak heat flux of $10.6 \mathrm{MW} / \mathrm{m}^{2}$ that approximates the heat distribution from the plasma edge modeling (Fig. 4) and is the sum of the uniformly radiated heat flux of $\sim 3 \mathrm{MW} / \mathrm{m}^{2}$ plus the average of 7.6 $\mathrm{MW} / \mathrm{m}^{2}$ over the peak. The heat penetrating the surface is first being absorbed into the heat capacity of the thermal boundary layer as the thermal gradient develops and then conducted deeper into the stream. Although there is some bulk heat generation from nuclear heating it is insignificant in the divertor heat transfer.

Smolentsev calculated ${ }^{5}$ the temperature rise in the divertor for this heat load and a Flinabe stream entering at $420^{\circ} \mathrm{C}$ and flowing at $10 \mathrm{~m} / \mathrm{s}$ (Fig. 5).[4,23-27] The temperature rises rapidly within a short distance due to the high heat flux and generally poor thermal conductivity of the Flinabe. The rise in temperature is about $135^{\circ} \mathrm{C}$. This, added to the bulk temperature of $420^{\circ} \mathrm{C}$ leaving the first wall, gives a peak of about $555^{\circ} \mathrm{C}$. This is higher than the allowable temperature of $510^{\circ} \mathrm{C}$ for the first wall, but is acceptable in the divertor where

\footnotetext{
${ }^{4}$ The rise in surface temperature for a (semi-infinite) solid target is the wellknown equation, $\mathrm{T}=\mathrm{q} / \mathrm{k}(\square \mathrm{t} / \square)$. For a fluid target with flow velocity, $\mathrm{v}$, and transit time, $t$, for crossing the strike point of the divertor, the modified equation has a dependence on the angle and flux expansion factor of $(\sin (\square) / f 1 x p)$, where the flux expansion factor is the ratio of the flux evaluated where the divertor flow intercepts the separatrix to the flux expansion at the location of a perpendicular target

${ }^{5}$ The model for Flibe uses an approach based on the standard "K-_" model to characterize turbulent flow plus features that treat MHD effects, since Flibe does have some electrical conductance. There is little effect on the thickness (or speed) of the flow but a significant effect on the heat transfer in the near surface. There are also issues to do with heat transfer enhancement due to the waviness of the first wall flow.
} 


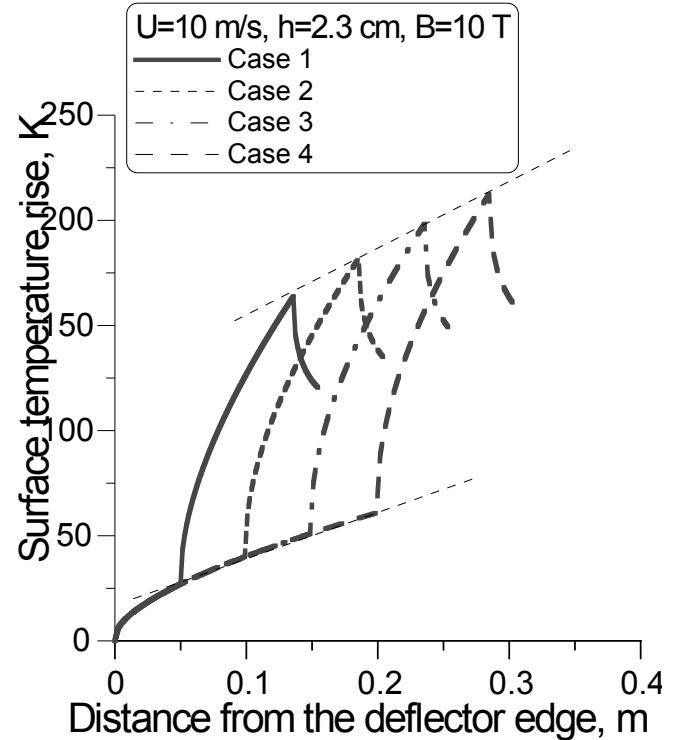

Figure 6. Surface temperature vs. distance from exit of deflector along divertor flow for four cases with the peak divertor heat flux located at 5 , 10,15 or $20 \mathrm{~cm}$ downstream from the deflector.

there is more shielding of impurities from the main plasma. In these results, the turbulence builds up in the layer adjacent to the deflector then drops after the flow leaves the deflector. Figure 6 shows the rise in surface temperature along the flow stream for cases with the peak heat load beginning at 0.05 , $0.10,0.15$ or $0.20 \mathrm{~m}$ from the exit of the deflector. The peak temperature is greater as the strike point gets further from the deflector. The initial temperature rise due to "preheating" from the $3 \mathrm{MW} / \mathrm{m}^{2}$ before the strike zone dominates for the cases shown, but the contribution from the decay in the turbulence becomes increasingly important. The implication our design is that the strike point should be within $0.15-0.2 \mathrm{~m}$ from the deflector to take advantage of the turbulence introduced in the deflector.

\section{ADDITIONAL FEATURES}

Previous Figure 1 includes several 3-D drawings of the outer deflector that indicate features associated with some of the important functions listed below.

- redirect first wall flow into duct (curve)

- align flow (fins)

- smooth surface of stream (finish)

- edges receding from plasma (shape)

- flow/spray cools duct and exposed walls (auxiliary stream)

While we expect most of the objectives above to be straightforward in a detailed design and engineering of the divertor, the smoothness of the surface of the stream and the conformity to the ideal location cannot be confirmed without testing, or at least, detailed computational fluid dynamic calculations. Space here does not permit an extended discussion of various points covered elsewhere. Several items, such as the shaping of the stream to avoid a "leading edge problem" at the sides, heating and cooling of the deflector, and provision for cooling of areas of the divertor and shield are described further in our longer paper[4] and in the Future R\&D Section of another paper[5].

\section{CLOSING REMARKS AND ACKNOWLEDGEMENTS}

Our hope is that advances in the design of power plants and control of plasmas can produce stable plasma configurations with sufficient radiation from the main plasma and from preferential sites in the plasma edge that the peak power to the divertor can be close to or lower than $10 \mathrm{MW} / \mathrm{m}^{2}$. While there are many unanswered questions and directions of investigation that would be important in advancing the divertor design, we believe our preliminary design work suggests that tractable solutions for a divertor with a flowing molten salt could be developed along the lines of the approach reported here.

A goal of the APEX and ALPS Programs is to investigate the potential of free liquid surfaces in fusion chamber technology. with a sufficient level of effort that the design issues can be resolved and an accurate assessment of this potential can be understood. We are supported by the APEX and ALPS Teams and a significant commitment by the Department of Energy's US Fusion Energy Science Program that has enabled us to utilize diverse expertise in plasma edge modeling, advanced mechanical and systems design, and heat transfer. The work of two authors (TDR and MER) was performed under the auspices of the U.S. Department of Energy by contractW7405-Eng-48 at University of California Lawrence Livermore National Laboratory.

\section{References}

[1] M. Abdou et al., "Exploring novel high power density concepts for attractive fusion systems," Fus. Eng. \& Des. 45 (1999) 145; see also http://www.fusion.ucla.edu/APEX/ (many presentations)

[2] R. Mattas and ALPS Team, "ALPS - Advanced Limiter-Divertor Plasma Facing Systems," Fus. Eng. \& Des. 49-50 (2000) 127; see also the ALPS website $<$ http://fusion.anl.gov/ALPS_Info_Center/calls.html $>$

[3] R.E. Nygren, T.D. Rognlien, M.E. Rensink, S. Smolentsev, B.E. Nelson, et al., A Fusion Reactor with a Liquid Molten Salt First Wall, elsewhere in this journal

[4] R.E. Nygren, M.A. Ulrickson, B.E. Nelson, P.J. Fogarty, C. Eberle, et al., Design Integration of Liquid Surface Divertors, to be pub. in FED

[5] R.E. Nygren, D.K. Sze, B.E. Nelson, P.J. Fogarty, C. Eberle, et al., A Fusion Reactor Design with a Liquid First Wall and Divertor, to be published in FED

[6] M.A. Tillack et al., "Engineering Design of the ARIES-RS Power Plant," Fus. Eng. \& Des. 41 (1998) 491

[7] C.P.C Wong, et al., "ARIES Divertor System - Selection and Analysis," FED 38, 1997 p115

[8] T.D. Rognlien, M.E. Rensink, "Interactions between liquid-wall vapor and edge plasmas," JNM 290-293 (2001) 312-316

[9] T.D. Rognlien and M.E. Rensink, "Edge-plasma properties in liquidwall environments," 8th Int. Workshop on Edge Plasma Theory in Fusion Devices, Helsinki, Finland, Sept. 10-12, 2001

[10] J.N. Brooks, D. Naujoks, Sheath superheat transmission due to redeposition of thermally emitted material, Physics of Plasmas 7 (2000) 2565

[11] D. Naujoks, J.N. Brooks, Combined sheath and thermal analysis of overheated surfaces in fusion devices, JNM. 290-293(2001) 1123

[12 J.N. Brooks, T.D. Rognlien, D.N. Ruzic and J.P. Allain, "Erosion/redeposition of lithium-based liquid surface divertors," JNM. 290-293(2001) 185

[13] J.N. Brooks, Modeling of sputtering erosion/redeposition - status and implications for fusion design, FED, 60 \#4 (July 2002) 515-526

[14] R. Bastasz and W. Eckstein, Plasma-Surface Interactions on Liquids, JNM 290-293 (2001) 19-24 
[15] R. Doerner, M.J. Baldwin, M.J., R.W. Conn, A.A. Grossman, S.C. Luckhardt, R. Seraydarian, G.R. Tynan, D.G. Whyte, "Measurements of erosion mechanisms from solid and liquid materials in PISCES-B," JNM, 290-293 (2001) p166-172; and M.J. Baldwin, R. Doerner, S.C. Luckhardt, R. Seraydarian, D.G. Whyte, R.W. Conn, "Plasma interaction with liquid lithium: Measurements of retention and erosion," FED, 61-62 (2002) p231

[16] J.P. Allain, M.D. Coventry, D.N. Ruzic, "Temperature dependence of liquid-lithium sputtering from oblique $700 \mathrm{eV}$ He ions," JNM, 313 (Mar 2003) p641-645

[17] J.P. Allain, D.N. Ruzic, M.R. Hendricks, "D, He and Li sputtering of liquid eutectic Sn-Li," JNM 290 (March 2001) p33-37, and J.P. Allain, D.N. Ruzic, M.R. Hendricks, "Measurements and modeling of D, He and Li sputtering of liquid lithium," JNM 290 (March 2001) p180-184

[18] M.J. Baldwin, R. Doerner, S.C. Luckhardt, R.W. Conn, "Deuterium retention in liquid lithium," Nucl. Fusion, 42 (2002) p1318-1323; and M.J. Baldwin, R. Doerner, R. Causey, S.C. Luckhardt, R.W. Conn, Recombination of deuterium atoms on the surface of molten Li-LiD," JNM, 306, (2002) p15-20

[19] R. Bastasz, "Surface Studies of Liquid Metals and Alloys", Proceedings of the International Symposium Material Chemistry in the Nuclear Environment (2002) in press

[20] K. Shimada, T. Tanabe, R. Causey, T. Venhaus, and K. Okuno, "Hydrogen recycling study by Balmer lines emissions in linear plasma machine TPE," J. Nucl. Mater. 290-293 (2001) 479

[21] J.P. Allain, M. Nieto, M.D. Coventry, M.J. Neumann, E.Vargas-Lopez, D.N. Ruzic, "FLIRE - flowing liquid surface retention experiment, design and testing," FED, 61-62, (Nov 2002) p245-250; and M. Nieto, D.N. Ruzic, J.P. Allain, M.D. Coventry, E.Vargas-Lopez, "Helium retention and diffusivity in flowing liquid lithium," JNM, 313 (Mar 2003) p646-650

[22] N. Morley et al., Modeling for liquid metal free surface MHD flow for fusion liquid walls, to be published in a special issue of FED; ; see also N. B. Morley, S. Smolentsev and D. Gao, Modeling infinite/axisymmetric liquid metal magnetohydrodynamic free surface flows, FED 63-64 (2002) 343-351

[23] S. Smolentsev, M. Abdou, N. Morley, A. Ying, T. Kunugi, "Application of the K-epsilon Model to Open Channel Flows in a Magnetic Field," Int. J. of Eng. Sci., accepted for publication (2001).

[24] S.Smolentsev, M. Abdou, T. Kunugi, "Development and Adjustment of K-epsilon Turbulence Model for MHD Channel Flows with Large Aspect Ratio in a Transverse Magnetic Field," Proc. $4^{\text {th }}$ Int. PAMIR Conf. on Magneto-hydrodynamics at Dawn of Third Millennium, Giens, France, 1 (2000) 21-26

[25] B.Freeze, S.Smolentsev, N.Morley, M.Abdou, "Characterization of surface waves and their effect on heat transfer in high Fr, high We open channel turbulent water flow," Int. J. Heat \& Mass Transfer, to be published

[26] H.Ueda, R.Moller, S.Komori, T.Mizushina, Eddy diffusivity near the free surface of open channel flow, Int. J. Heat Mass Transfer 20 (1977) 1127

[27] S. Smolentsev et al, “ “, to be published in a special issue of FED 